\title{
ANNELIDS IN EVOLUTIONARY DEVELOPMENTAL BIOLOGY AND COMPARATIVE GENOMICS
}

\author{
MCDOUGALL C.*,**, HUI J.H.L.**, MONTEIRO A.**, TAKAHASHI T.****** \& FERRIER D.E.K.*,**
}

\section{Summary:}

Annelids have had a long history in comparative embryology and morphology, which has helped to establish them in zoology textbooks as an ideal system to understand the evolution of the typical triploblastic, coelomate, protostome condition. In recent years there has been a relative upsurge in embryological data, particularly with regard to the expression and function of developmental control genes. Polychaetes, as well as other annelids such as the parasitic leech, are now also entering the age of comparative genomics. All of this comparative data has had an important impact on our views of the ancestral conditions at various levels of the animal phylogeny, including the bilaterian ancestor and the nature of the annelid ancestor. Here we review some of the recent advances made in annelid comparative development and genomics, revealing a hitherto unsuspected level of complexity in these ancestors. It is also apparent that the transition to a parasitic lifestyle leads to, or requires, extensive modifications and derivations at both the genomic and embryological levels.

KEY WORDS : Polychaetes, clitellates, bilaterian, Hox, ParaHox.

T o understand the evolution of any taxon or character a phylogenetic framework is required to structure any comparisons. Great strides have been made in refining the phylogeny of the animals, and of the annelids, with the input of molecular data (reviewed in the accompanying paper of Bleidorn). In the context of the annelids (segmented worms) they are one of the most prominent taxa within the Lophotrochozoa, one of the three great clades of the bilaterally symmetrical, triploblastic animals (the Bilateria); the other two superclades being the Ecdysozoa (moulting animals including insects, crabs, nematodes/roundworms and priapulids/penis worms) and the Deuterostomia (animals whose mouth develops from a secondary opening during embryogenesis, including sea urchins, acorn worms, sea squirts and humans) (Fig. 1) (Aguinaldo et

* The Gatty Marine Laboratory, School of Biology, University of St Andrews, St Andrews, Fife, KY16 8LB, UK.

** Department of Zoology, University of Oxford, South Parks Road, Oxford, OX1 3PS, UK.

**** Present address, Faculty of Life Sciences, Michael Smith Building, University of Manchester, Oxford Road, Manchester, M13 9PT, UK. Correspondence: Ferrier D.E.K., The Gatty Marine Laboratory, School of Biology, University of St Andrews, St Andrews, Fife, KY16 8LB, UK. Tel.: +44 (0)1334 463480 - E-mail: dekf@st-andrews.ac.uk al., 1997; de Rosa et al., 1999). Although the precise membership of each of these three super-clades is still being refined their existence seems well supported and justifiable. The phylogeny within the Lophotrochozoa, and the positions of the annelid groups within it is less robustly resolved. However, a consensus that is rapidly gaining support is that the annelids now include the polychaetes (bristle worms) and clitellates (the leeches and oligochaetes), along with other groups that have had a rather nomadic phylogenetic history, including the Pogonophora/Siboglinidae (beard worms), the Echiura (spoon worms), the Sipuncula (peanut worms) and the Myzostomida (parasites and commensals of crinoid feather stars). The emerging consensus from the molecular data is that the polychaetes are a paraphyletic group with the Clitellata, Sipuncula, Echiura, Siboglinidae and Myzostomidae embedded within it (Bleidorn et al., 2007; Struck et al., 2007).

\section{ANCESTRAL EMBRYOLOGY AND DEVELOPMENT}

\section{THE BILATERIAN ANCESTOR}

1 The "new" phylogeny has led to the abandonment of the traditional prominence of the coelom as a phylogenetically robust and informative character, with the pseudocoelomate nematodes now being loosely related to the eucoelomate arthropods (in the Ecdysozoa) (Fig. 1). The well-established developmental biology model system of the nematode Caenorhabditis elegans can thus no longer be taken as an outgroup for comparison to the other traditional models of fruit flies (Drosophila melanogaster) and vertebrates (such as the mouse, zebrafish, chick and frog). The importance of the development of model systems within the lophotrochozoans is now undeniable. Lophotrochozoan models will help distinguish patterns of true conservation between the ecdysozoans and deuterostomes from convergence, and reveal patterns of loss and derivation (Tessmar-Raible \& Arendt, 2003; Weisblat \& Huang, 2001). 
Fig. 1. - Schematic of the animal phylogeny, showing selected phyla and the location of the Annelida in the Lophotrochozoa group of protostomes.

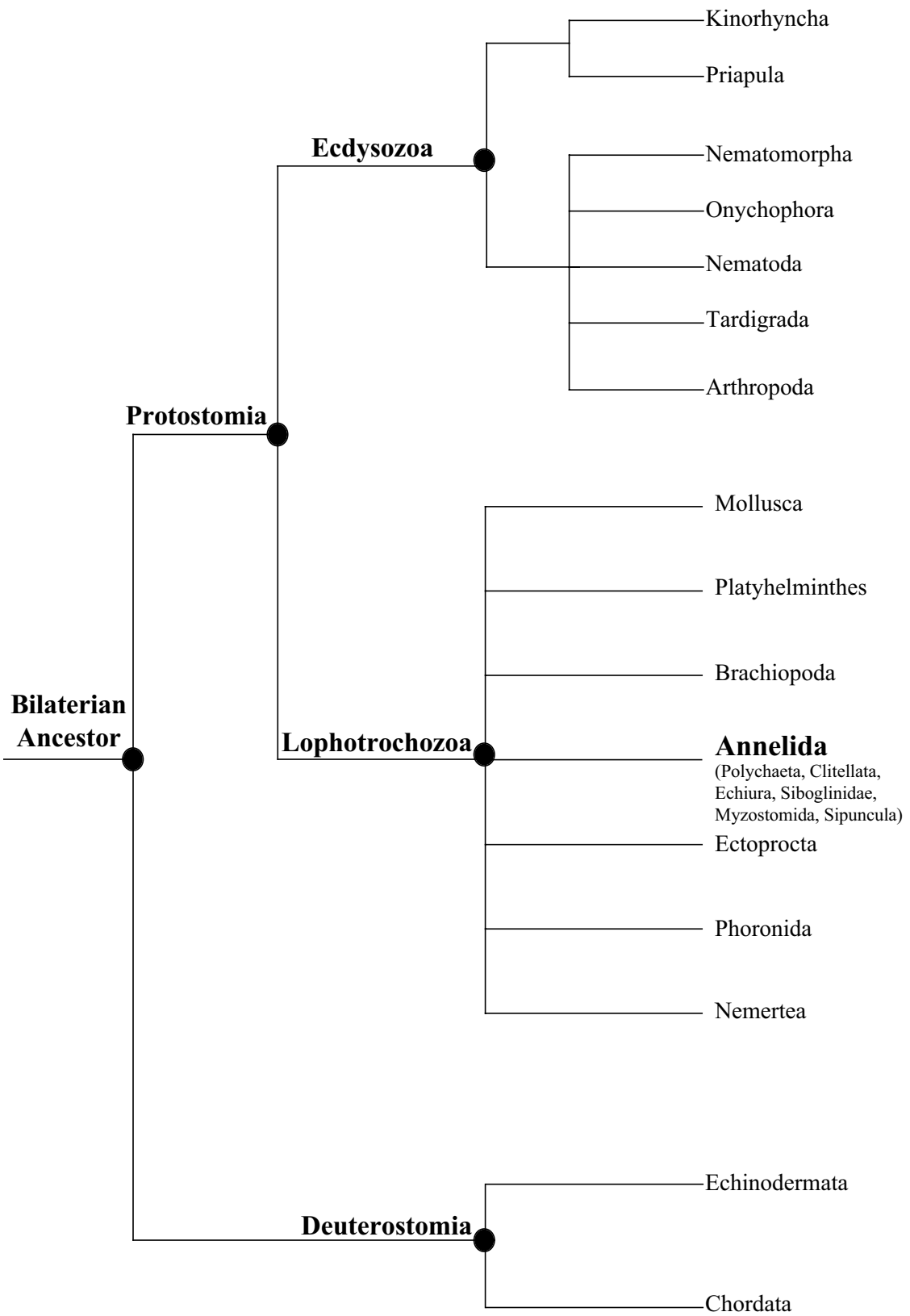

Inherent in this field of research are assessments of whether similarities reflect convergence or conservation. There are many pitfalls, but one guiding principle is that if two characters resemble each other to a high degree of complexity (e.g. detailed gene expression and networks) then they are much more likely to reflect conservation from a common ancestor that also possessed the gene network(s), and possibly the morphological or developmental character specified by this network. One proviso is that developmental gene networks are often reused during development in nonhomologous contexts (e.g. Lowe \& Wray, 1997; Seaver et al., 2001 and references therein). Also retention of an ancestral network and character in only a few lineages with repeated independent loss amongst many other lineages can confuse the picture. Such loss of characters is clearly a plausible and common phenomenon (e.g. Jenner 2004; Bleidorn 2007). At present we tend to then fall back on supposing that this rare retention of ancestral complexity can be revealed by the same complex genetic network being used in such supposed non-derived lineages. The validity of this supposition will become clearer as more is revealed about the developmental mechanisms and networks operating in a greater diversity of taxa both across the animal kingdom and within phyla.

A table of recent publications on annelid development that impact on our understanding of the form of the ancestral bilaterian is given in Table I (see also Irvine \& Seaver, 2006). These deductions summarized in Table I 
Centralised nervous system

Eyes - ciliary and rhabdomeric components

Sensory-Neurosecretory cells

Beta-catenin in binary cell-fate decisions

Convergent extension of embryo

Germ cell specification by Vasa \& Nanos

Segmented?

Mesoderm differentiation controlled by Twist and Snail

Germ layer-specific differentiation by GATA genes

Posterior growth zone

Larval apical organ?
Denes et al., 2007

Arendt et al., 2004

Tessmar-Raible et al., 2007

Schneider \& Bowerman, 2007

Steinmetz et al., 2007

Rebscher et al., 2007; Kang et al., 2002

Yes - Prud'homme et al., 2003

No - Seaver et al., 2001

Dill et al., 2007

Gillis et al., 2007

De Rosa et al., 2005; Seaver et al., 2005

Nielsen, 2005

Table I. - Some features of the ancestral bilaterian deduced with contributions of annelid molecular data.

are based on the discovery of similar developmental mechanisms between annelids and members of at least one or other of the ecdysozoan or deuterostome clades. Interestingly it is usually the deuterostomes, and even vertebrates, that show the greater degrees of similarity to annelids than the other traditional protostome (and specifically ecdysozoan) model systems of flies and nematodes.

\section{THE ANNELID ANCESTOR}

With these reconstructions of the bilaterian ancestor there are clearly implications for the nature and form of the annelid ancestor. Undoubtedly the annelid ancestor was segmented, but there is still a debate as to whether the mechanism(s) producing this segmentation was(were) homologous to segmentation mechanisms operating elsewhere in the animal kingdom, in the arthropods or chordates. The annelid ancestor also had a centralized nervous system, built with developmental networks conserved with the vertebrates (Denes et al., 2007). Whether the annelid ancestor, or even the last common ancestor of the ecdysozoans and lophotrochozoans, underwent some degree of moulting is an intriguing possibility (Paxton, 2005). Furthermore the paraphyly of the polychaetes has implications for the origin of the clitellates. Again segmentation is an issue, with different modes apparently operating in polychaetes versus clitellates (Shimizu \& Nakamoto, 2001; Irvine \& Seaver, 2006). Also the annelid ancestor clearly underwent indirect development via a trochophore larva (Fig. 2E) (this developmental mode being the norm for polychaetes). Many clitellates have subsequently lost this mode of development, and are now direct developers. It seems likely that this is due to changes in the life history of these clitellates. Terrestrialisation is clearly one key aspect of the life of clitellates such as the oligochaetous earthworm. In clitellates as a whole, even those that have remained aquatic (Fig. 2D) (or returned to an aquatic life-style, e.g. Erséus, 2005; Westheide et al.,
1999), a reproductive process has evolved which involves the clitellum and the formation of a cocoon in which the embryos are nourished on a supply of yolk and have done away with the requirement for a feeding trochophore larva. Further to this, development

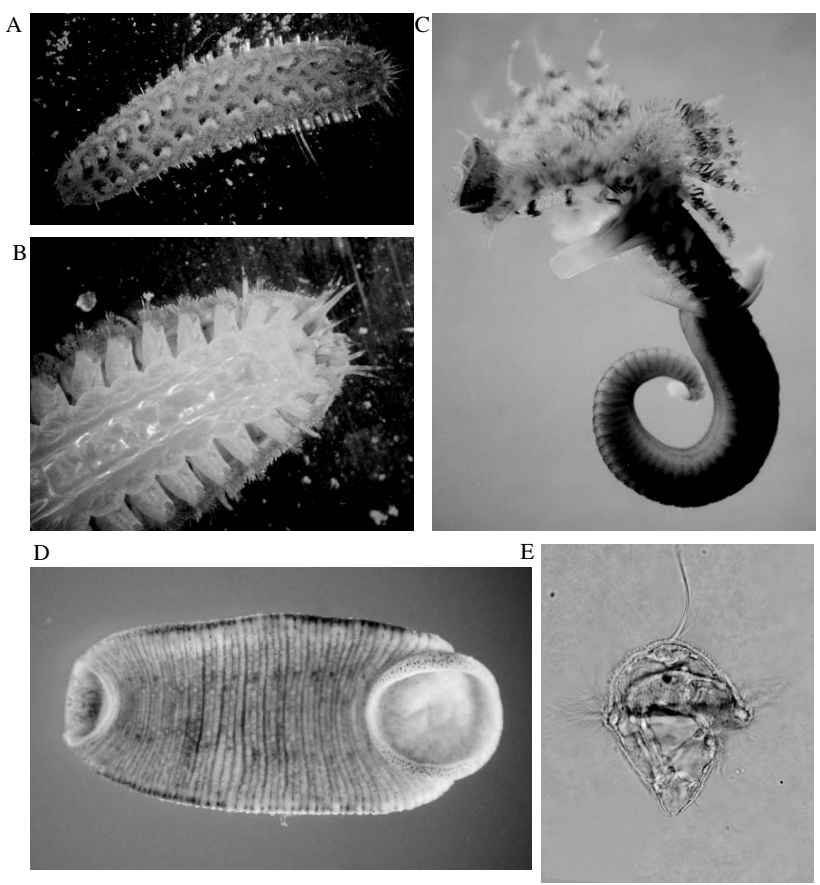

Fig. 2. - Variety of form in the annelids. (A) Dorsal view of the scale worm, Lepidonotus (Polynoidae), bearing many of the features of the description of the ancestral annelid from Westheide (1997). (B) Ventral view of the anterior end of Lepidonotus, revealing the parapodial appendages with chaetae, and the palps and antennae anterior to the mouth. (C) Pomatoceros lamarckii adult; a polychaete with a heteronomous trunk, rather than the homonomous trunk of Lepidonotus. (D) Ventral view of the Clitellate leech, Theromyzon tessulatum, showing the distinctive anterior (left) and posterior (right) suckers. (E) A trochophore larva of P. lamarckii, with prominent apical tuft (upwards) above the mass of cells of the apical organ, just above the brown, algae-filled stomach. The mouth is on the right, just beneath the long cilia of the prototroch. Phyla with TROCHOphore-like larvae form an important component of the LophoTROCHOzoa. 
via large teloblast cells is employed by the leech and oligochaetes (Weisblat \& Huang, 2001; Bergter et al., 2004), and the evolutionary relationship between these leech teloblasts and cells in the posterior growth zone of polychaetes is an important issue to be resolved (de Rosa et al., 2005; Shimizu \& Nakamoto, 2001; Seaver et al., 2005).

The discussions on the reconstruction of the annelid and clitellate ancestors have been reviewed in greater detail elsewhere (e.g. Bartolomaeus et al., 2005; Bleidorn, 2007; Nielsen, 2001; Purschke, 2002; Rouse \& Fauchald, 1997; Rouse \& Pleijel, 2001; Westheide, 1997; Westheide et al., 1999). There is still plenty of debate about the form of these ancestors in addition to the processes outlined above. These are summarised in Table II, which outlines the development of ideas and debates since the (contentious) conclusion of Westheide (1997) that "the basic annelid body plan" consisted of: 1) homonomous segmentation (e.g. Fig. 2A); 2) biramous parapodia with numerous chaetae; 3) dorsal bristles with a protective function (Fig. 2A); 4) gonads in all segments; 5) metanephridia; 6) prostomium with paired palps and presumably three antennae (Fig. 2B); 7) nuchal organs; 8) simple ciliated foregut (dorsolateral folds), at least in the juvenile stages; 9) collagen cuticle; 10) epibenthic mode of life. As the molecular development and morphology of a wider range of annelid taxa is investigated we will gain a better appreciation of the extent of conservation or diversity of mechanisms operating in the annelids, and hence the most likely ancestral modes of development and composition of characters/morphological features. This will permit a more robust comparison to other taxa for reconstruction of such states as the bilaterian ancestor, and will also permit a clearer resolution of how lineages such as the parasitic leeches evolved within the annelids.

\section{GENOME EVOLUTION}

The logic employed above for reconstruction of ancestral forms, reasoning that highly complex similarities denote conservation from an ancestor, still involves a degree of subjectivity on just how complex does something have to be before it is considered too complex to have evolved convergently (notwithstanding the, as yet, poorly quantified frequency of cooption of entire complex developmental networks and mechanisms into new or non-homologous situations)! An alternative aspect of ancestral reconstruction, that is perhaps based on less subjective grounds, is that of deducing gene content and organisation in an ancestor. More easily and readily established quantifiable criteria can be used for assessing homology, such as levels of sequence similarity and patterns of branching in gene phylogenies, along with locations in the genome. Sequence comparisons are undoubtedly subject to their own forms of artefacts and biases (e.g. Long Branch Attraction, or orthology judgements being confounded by gene duplications and losses), but these are more easily quantified and detected than in morphological and developmental comparisons, and in these days of burgeoning amounts of sequence data many of the problems can be relatively easily overcome by the addition of further data.

Some examples of large-scale genomic resources that are now available, or are soon to be accessible, are

\section{Character in ancestral annelid}

\section{References}

Prominent parapodia?

Circular muscles (lacking)?

Nuchal organs

Lateral organs

Palps \& antennae

Segmented, but by multiple mechanisms?

Nephridia:

- Mesodermal contributions to nephridia?

Ancestral connectivity with coelomoducts?

- Protonephridia/head kidneys plesiomorphic?

Protonephridia and metanephridia homologous?

Foregut with dorsolateral ciliated folds

Brooding or broadcast spawning?

Cleavage, equal or unequal?

Lecithotrophic or planktotrophic?

Anterior or posterior (or both) contributions to nervous system

Moulting?

Collagenous cuticle
Nielsen, 2001

Tzetlin \& Filippova, 2005; McDougall et al., 2006; Rüchel \& Muller, 2007

Purschke, 2005

Purschke \& Hausen, 2007

Purschke, 2002

Prud'homme et al., 2003; Seaver et al., 2005; Shimizu \& Nakamoto, 2001; Irvine \& Seaver, 2006

- Reviewed in Rouse \& Fauchald, 1997

- Bartolomaeus \& Quast, 2005

Purschke, 2002

Rouse, 2005

Dorresteijn, 2005

Rouse, 2000

Orrhage \& Muller, 2005; McDougall et al., 2006; Voronezhskaya

et al., 2003

Paxton, 2005

Purschke, 2002

Table II. - Some potential features of the ancestral annelid. 
the whole genome of the polychaete Capitella spI, and the leech Helobdella robusta, along with large collections of EST data from Riftia pachyptila (a deep-sea tubeworm) and Alvinella pompejana (a polychaete that lives by deep-sea hydrothermal vents), all from the Joint Genome Institute (JGI) (http://www.jgi.doe.gov/). These will be supplemented by a large set of EST data from the polychaete Platynereis dumerilii, from Genoscope, and smaller EST sets from a variety of other annelids from individual groups and networks around the world (e.g. AToL, http://collections.oeb.harvard. edu/Invertebrate/atol/species.cfm; Takahashi et al., in prep.; LumbriBASE, http://www.earthworms.org/).

Here we briefly summarize some recent examples that indicate the less derived nature of polychaete genomes, relative to the traditional protostome genome models of fruit flies and nematodes. The less derived nature of the genome seems to correlate with the less derived embryology and developmental networks highlighted in Table I. Also, in the context of understanding the evolution of a parasite such as the leech, this polychaete data provides an excellent framework from which we can deduce the evolutionary novelties and derivations that subsequently arose at the origin of the clitellates and the parasitic leech itself.

It has recently been shown that the polychaete Platynereis dumerilii has retained much more of the ancestral bilaterian gene organisation, in terms of retention of ancestral introns, compared to other invertebrate model systems (Raible et al., 2005). The conclusion from this annelid data is that the bilaterian ancestor had genes that were more intron-rich than had previously been appreciated, and that the Platynereis organisation was more closely comparable to the gene structure found in humans than to flies, nematodes or sea squirts. This less derived nature of the Platynereis genes also extends to their sequence. Raible et al. (2005) found that the branch lengths in molecular phylogenetic trees built from protein sequences were clearly shorter in this polychaete, relative to other invertebrate models, implying a greater similarity to the sequences that were present in the ancestral bilaterian. Specific examples of gene families that also illustrate this relative lack of derivation are also available. For example the immunerelated genes of Platynereis have greater similarity to those of deuterostomes than those of ecdysozoans (Altincicek \& Vilcinskas, 2007), and the GATA genes are similarly 'short-branch' (Gillis et al., 2007) in addition to all of the genes reported in the references given in Table I.

Organisms with "short-branch" sequences are very useful for phylogenetics. Another way that gene sequences can be used for phylogenetic purposes is as presence/ absence characters, rather than building phylogenetic trees from sequence alignments. One of the clearest examples of this is found with the Hox genes in lopho- trochozoans such as the annelids Nereis virens, Helobdella robusta and Hirudo medicinalis (de Rosa et al., 1999). Lophotrochozoans, such as these annelids, have Posterior Hox genes (Post1 and Post2) that are distinct from the Posterior Hox genes of deuterostomes and ecdysozoans, and which presumably arose via independent tandem duplications from those that generated the deuterostome and ecdysozoan Posterior Hox genes. The presence of Post1 and Post2, as distinct from ecdysozoan AbdB or deuterostome Hox9-15 sequences, can be taken as a character that unites the lophotrochozoans. Similarly the lophotrochozoans are distinguished by diagnostic central Hox gene sequences as well, such as Lox2, Lox4 and Lox 5 (de Rosa et al., 1999; Balavoine et al., 2002).

The Hox cluster genes pattern the development of the anterior-posterior axis of bilaterian embryos (Lemons $\&$ McGinnis, 2006). Changes in the expression of these genes can have a role in morphological evolution (e.g. Averof \& Patel, 1997; Cohn \& Tickle, 1999; Mahfooz et al., 2007), and the expression of Hox genes is conventionally thought to be linked to their organisation in ordered clusters (Duboule \& Morata, 1994). The relationship between cluster organisation and gene expression has been most clearly demonstrated in the mouse (Kmita \& Duboule, 2003). However the relationship between cluster organisation and gene function has become more ambiguous as the organisation of more Hox genes and clusters has been elaborated, with increasing numbers of examples of Hox clusters being broken and disrupted (e.g. Seo et al., 2004; Pierce et al., 2005; and reviewed in Ferrier \& Minguillón, 2003; Monteiro \& Ferrier, 2006). It has been hypothesised that mechanisms producing the progressive temporal sequence of activation of Hox genes along a cluster (Temporal Colinearity) are responsible for the principle constraint on ordered clusters (reviewed in Ferrier \& Holland, 2002; Ferrier \& Minguillón, 2003), even if these mechanisms might not be homologous across the animal kingdom (Ferrier, 2007; Monteiro \& Ferrier, 2006). This hypothesis has recently been questioned by Hox expression data from the polychaetes Platynereis dumerilii and Nereis virens (Kulakova et al., 2007), in which spatial colinearity seemed to be more apparent than temporal colinearity. The major caveat in interpreting such expression data is whether the organisation of the Hox genes is known. Simply extrapolating from the presumed ancestral condition of an ordered cluster without actually knowing the organisation of the cluster, and the order of the genes in an intact cluster, can be misleading. Not only are many Hox "clusters" being shown not to be clusters, but even when a cluster is intact the order of the genes could well be scrambled, as in the example of the purple sea urchin (Cameron et al., 2006). Cluster organisation can even vary between closely related species in the same genus. For example 
Drosophila clusters are broken in different places (reviewed in Negre \& Ruiz, 2007).

An alternative to evolution via gene expression alterations can be via gene gain or loss. For example the retention of many developmental control genes after the whole genome duplications at the origin of the vertebrates is hypothesized to have contributed to the evolution of the complexity of vertebrates (Shimeld \& Holland, 2000). Duplication of Hox genes is certainly not restricted to the vertebrate lineage (Schwager et al., 2007; Cartwright et al., 1993; de Rosa et al., 1999). Leeches are reported as having duplications of some Hox genes, although as yet there is no evidence for whole cluster duplications in these annelids. The Hox 4 and Hox 5 duplicates in leeches however have yet to be characterised from a single species, the Hox 4 "duplicates" of Lox6 and Lox18 having been cloned from Helobdella robusta and $H$. triserialis respectively, and the Hox 5 'duplicates' of Lox20 and Lox1 having been cloned from $H$. triserialis and Hirudo medicinalis respectively (Aisemberg \& Macagno, 1994; Kourakis et al., 1997; Kourakis \& Martindale, 2001). A clearer example of gene duplication in leeches is found with the Xlox ParaHox gene of H. medicinalis, Lox3, which has duplicated up to at least three tandemly arrayed copies (Wysocka-Diller et al., 1995). In concert with these potential duplications Irvine and Seaver (2006) speculate that leeches may also have undergone loss of the Hox genes orthologous to Hox2, Hox3, Post1 and Post2. Such turmoil in the Hox and ParaHox gene composition is not representative for the annelids as a whole as a full complement of the expected Hox and ParaHox genes, without any further duplications, is found in the polychaetes $P$. dumerilii (Monteiro et al., in prep.; Hui et al., in prep.) and Capitella spI (Fröbius \& Seaver, 2006; http://www.jgi.doe.gov/).

Will polychaete genome organisation prove to be less derived than the genomes of flies and nematodes, and have retained a greater amount of the ancestral organisation than the other protostome models? Almost certainly yes if gene sequence, content and organisation are anything to go by. Moving 'into' the annelids however, to the parasitic leeches, the genes of the Hox and ParaHox families may be indicative of more extensive lineage-specific novelties and rearrangements, which should become more clearly apparent once a leech genome is available.

With the invention of new, cheaper sequencing technologies the prospect of many more genomes being "done", at least to a low level of coverage, is much greater. Reference genomes, with a higher quality of assembly, could then be constructed for those animals with extra gene mapping techniques available, such as chromosomal Fluorescence In Situ Hybridisation (FISH) (e.g. Hui et al., 2007). These new technologies and this wealth of data provide a goldmine of opportunities for understanding both ancestral genome organisation and lineage-specific derivations.

\section{ACKNOWLEDGEMENTS}

W e would like to thank Eric Viscogliosi for the invitation to the EMOP10 and the opportunity to contribute this paper, and Joanne Ferrier and Suleyman Kuyumcu for comments on the manuscript. Work in the authors' laboratory is funded by the BBSRC.

\section{REFERENCES}

Aguinaldo A.M. et al. Evidence for a clade of nematodes, arthropods and other moulting animals. Nature, 1997, 387, 489-493.

Aisemberg G.O. \& Macagno E.R. Lox1, an Antennapedia-class homeobox gene, is expressed during leech gangliogenesis in both transient and stable central neurons. Dev. Biol., 1994, 161 (2), 455-465.

Altincicek B. \& VilcinsKas A. Analysis of the immune-related transcriptome of a lophotrochozoan model, the marine annelid Platynereis dumerilii. Frontiers Zool., 2007, 4, 18.

ARENDT D. et al. Ciliary photoreceptors with a vertebrate-type opsin in an invertebrate brain. Science, 2004, 306, 869871.

Averof M. \& Patel N.H. Crustacean appendage evolution associated with changes in Hox gene expression. Nature, 1997, 388, 682-686.

Balavoine G., De Rosa R. \& Adoutte A. Hox clusters and bilaterian phylogeny. Mol. Phyl. Evol., 2002, 24, 366-373.

Bartolomaeus T., Purschke G. \& Hausen H. Polychaete phylogeny based on morphological data - a comparison of current attempts. Hydrobiologia, 2005, 535/536, 341-356.

Bartolomaeus T. \& Quast B. Structure and development of nephridia in Annelida and related taxa. Hydrobiologia, 2005, 535/536, 139-165.

Bergter A., Lothar A., Beck L.A. \& Paululat A. Embryonic development of the oligochaete Enchytraeus coronatus: an SEM and histological study of embryogenesis from onecell stage to hatching. J. Morphol., 2004, 261, 26-42.

BLEIDORN C. The role of character loss in phylogenetic reconstruction as exemplified for the Annelida. J. Zool. Syst. Evol. Res., 2007, doi:10.1111/j.1439-0469.2007.00425.x

BLEIDORN C. et al. Mitochondrial genome and nuclear sequence data support Myzostomida as part of the annelid radiation. Mol. Biol. Evol., 2007, 24, 1690-1701.

CAmeron R.A. et al. Unusual gene order and organization of the sea urchin hox cluster. J. Exp. Zoolog. B. Mol. Dev. Evol., 2006, 306, 45-58.

Cartwright P., Dick M. \& Buss L.W. HOM/Hox type homeoboxes in the chelicerate Limulus polyphemus. Mol. Phyl. Evol., 1993, 2 (3), 185-192.

Cohn M.J. \& Tickle C. Developmental basis of limblessness and axial patterning in snakes. Nature, 1999, 399, 474-479. 
De Rosa R. et al. Caudal and even-skipped in the annelid Platynereis dumerilii and the ancestry of posterior growth. Evol. Dev., 2005, 7 (6), 574-587.

De Rosa R. et al. Hox genes in brachiopods and priapulids and protostome evolution. Nature, 1999, 399, 772-776.

DENEs A.S. et al. Molecular architecture of annelid nerve cord supports common origin of nervous system centralization in Bilateria. Cell, 2007, 129, 277-288.

Dill K.K., Thamm K. \& Seaver E.C. Characterization of twist and snail gene expression during mesoderm and nervous system development in the polychaete annelid Capitella sp. I. Dev. Genes Evol., 2007, 217, 435-447.

Dorresteijn A. Cell lineage and gene expression in the development of polychaetes. Hydrobiologia, 2005, 535/536, 122.

Duboule D. \& Morata G. Colinearity and functional hierarchy among genes of the homeotic complexes. Trends Genet., 1994, 10 (10), 358-364.

ERsÉus, C. Phylogeny of oligochaetous Clitellata. Hydrobiologia, 2005, 535/536, 357-372

FERriER D.E.K. Evolution of Hox gene clusters, in: Hox gene expression. Papageorgiou S. (ed.), Springer, Landes Bioscience, 2007, 53-67.

Ferrier D.E.K. \& Holland P.W.H. Ciona intestinalis ParaHox genes: evolution of Hox/ParaHox cluster integrity, developmental mode, and temporal colinearity. Mol. Phyl. Evol., 2002, 24, 412-417.

Ferrier D.E.K. \& Minguillón C. Evolution of the Hox/ParaHox gene clusters. Int. J. Dev. Biol., 2003, 47, 605-611.

Fröbius A.C. \& Seaver E.C. ParaHox gene expression in the polychaete annelid Capitella sp. I. Dev. Genes Evol., 2006, 216 (2), 81-88.

Gillis W.J., Bowerman B. \& SchneIder S. Ectoderm- and endomesoderm-specific GATA transcription factors in the marine annelid Platynereis dumerilii. Evol. Dev., 2007, 9 (1), 39-50.

HuI J.H.L. et al. Duplication of the ribosomal gene cluster in the marine polychaete Platynereis dumerilii correlates with ITS polymorphism. J. Mar. Biol. Ass. UK, 2007, 87, 443-449.

IRVINE S.Q. \& SEAVER E.C. Early annelid development, a molecular perspective, in: Reproductive biology and phylogeny of Annelida. Rouse G. \& Pleijel F. (eds), Science Publishers, Enfield, New Hampshire, 2006, 93-140.

JENNER R.A. When molecules and morphology clash: reconciling conflicting phylogenies of the Metazoa by considering secondary character loss. Evol. Dev., 2004, 6, 372-378.

Kang D., Pilon M. \& Weisblat D.A. Maternal and zygotic expression of a nanos-class gene in the leech Helobdella robusta: primordial germ cells arise from segmental mesoderm. Devel. Biol., 2002, 245, 28-41.

Kmita M. \& Duboule D. Organizing axes in time and space; 25 years of colinear tinkering. Science, 2003, 301, 331-333.

Kourakis M.J., et al. Conserved anterior boundaries of Hox gene expression in the central nervous system of the leech Helobdella. Dev. Biol., 1997, 190 (2), 284-300.

Kourakis M.J. \& Martindale M.Q. Hox gene duplication and deployment in the annelid leech Helobdella. Evol. Dev., 2001, 3 (3), 145-153.
Kulakova M. et al. Hox gene expression in larval development of the polychaetes Nereis virens and Platynereis dumerilii (Annelida, Lophotrochozoa). Dev. Genes Evol., 2007, 217, 39-54.

Lemons D. \& McGinnis W. Genomic evolution of Hox gene clusters. Science, 2006, 313, 1918-1922.

LOWE C.J. \& WRAY G.A. Radical alterations in the roles of homeobox genes during echinoderm evolution. Nature, 1997, 389, 718-721.

MAHFOOZ N. et al. Ubx regulates differential enlargement and diversification of insect hind legs. PLOS ONE, 2007, 9, e866.

McDougall C. et al. The development of the larval nervous system, musculature and ciliary bands of Pomatoceros lamarckii (Annelida): heterochrony in polychaetes. Frontiers Zool., 2006, 3, 16.

Monteiro A.S. \& Ferrier D.E.K. Hox genes are not always colinear. Int. J. Biol. Sci., 2006, 2, 95-103.

Negre B. \& Ruiz A. HOM-C evolution in Drosophila: is there a need for Hox gene clustering? Trends Genet., 2007, 23 (2), 55-59.

NieLsen C. Animal evolution: interrelationships of the living phyla. Oxford University Press, 2001.

Nielsen C. Larval and adult brains. Evol. Dev., 2005, 7 (5), 483-489.

OrRhage L. \& MÜLler M.C.M. Morphology of the nervous system of Polychaeta (Annelida). Hydrobiologia, 2005, 535/ 536, 79-111.

PAXTON H. Molting polychaete jaws - ecdysozoans are not the only molting animals. Evol. Dev., 2005, 7 (4), 337-340.

PIERCE R.J. et al. Evidence for a dispersed Hox gene cluster in the platyhelminth parasite Schistosoma mansoni. Mol. Biol. Evol., 2005, 22 (12), 2491-2503.

Prud'homme B. et al. Arthropod-like expression patterns of engrailed and wingless in the annelid Platynereis dumerilii suggest a role in segment formation. Curr. Biol., 2003, 13, 1876-1881.

Purschke G. On the ground pattern of Annelida. Org. Divers. Evol., 2002, 2, 181-196.

Purschke G. Sense organs in polychaete (Annelida). Hydrobiologia, 2005, 535/536, 53-78.

Purschke G. \& Hausen H. Lateral organs in sedentary polychaetes (Annelida) - ultrastructure and phylogenetic significance of an insufficiently known sense organ. Acta Zool., 2007, 88, 23-39.

RAIBLE F. et al. Vertebrate-type intron-rich genes in the marine annelid Platynereis dumerilii. Science, 2005, 10, 13251326.

REBSCHER N. et al. Vasa unveils a common origin of germ cells and of somatic stem cells from the posterior growth zone in the polychaete Platynereis dumerilii. Devel. Biol., 2007, 306, 599-611.

Rouse G.W. \& Fauchald K. Cladistics and polychaetes. Zool. Scr., 1997, 26 (2), 139-204.

Rouse G.W. \& Pleijel F. Polychaetes. Oxford University Press, 2001.

Rouse G.W. Annelid sperm and fertilization biology. Hydrobiologia, 2005, 535/536, 167-178. 
RÜCHEL J. \& MüLlER M.C.M. F-actin framework in Spirorbis cf. spirorbis (Annelida: Serpulidae): phalloidin staining investigated and reconstructed by cLSM. Invert. Biol., 2007, 126 (2), 173-182.

SCHNEIDER S.Q. \& BowERman B. Beta-catenin asymmetries after all animal/vegetal-oriented cell divisions in Platynereis dumerilii embryos mediate binary cell-fate specification. Devel. Cell., 2007, 13, 73-86.

SCHWAger E.E. et al. Duplicated Hox genes in the spider Cupiennius salei. Frontiers Zool., 2007, 4, 10.

SEAVER E.C. et al. The spatial and temporal expression of $\mathrm{Ch}$ en, the engrailed gene in the polychaete Chaetopterus, does not support a role in body axis segmentation. Devel. Biol., 2001, 236, 195-209.

Seaver E.C., Thamm K. \& Hill S.D. Growth patterns during segmentation in the two polychaete annelids, Capitella sp. I and Hydroides elegans: comparisons at distinct life history stages. Evol. Dev., 2005, 7 (4), 312-326.

SEO H.C. et al. Hox cluster disintegration with persistent anteroposterior order of expression in Oikopleura dioica. Nature, 2004, 431, 67-71.

Shimeld S.M. \& Holland P.W.H. Vertebrate innovations. Proc. Natl. Acad. Sci. USA, 2000, 97 (9), 4449-4452.

Shimizu T. \& NAKAмото A. Segmentation in annelids: cellular and molecular basis for metameric body plan. Zool. Sci., 2001, 18, 285-298.

STEINMETZ P.R.H. et al. Polychaete trunk neuroectoderm converges and extends by mediolateral cell intercalation. Proc. Natl. Acad. Sci. USA, 2007, 104 (8), 2727-2732.

STRuCK T.H. et al. Annelid phylogeny and the status of Sipuncula and Echiura. BMC Evol. Biol., 2007, 7, 57.

Tessmar-Raible K. \& Arendt D. Emerging systems: between vertebrates and arthropods, the Lophotrochozoa. Curr. Opin. Genet. Dev., 2003, 13 (4), 331-340.

Tessmar-Raible K. et al. Conserved sensory-neurosecretory cell types in annelid and fish forebrain: insights into hypothalamus evolution. Cell, 2007, 129, 1389-1400.

Tzetlin A.B. \& Filippova A.V. Muscular system in polychaetes (Annelida). Hydrobiologia, 2005, 535/536, 113-126.

Voronezhskaya E.E., Tsitrin E.B. \& NezLIN L.P. Neuronal development in larval polychaete Phyllodoce maculata (Phyllodocidae). J. Comp. Neurol., 2003, 455, 299-309.

Weisblat D.A. \& Huang F.Z. An overview of glossiphoniid leech development. Can. J. Zool., 2001, 79, 218-232.

WESTHEIDE W. The direction of evolution within the Polychaeta. J. Nat. Hist., 1997, 31, 1-15.

Westheide W. et al. Systematization of the Annelida: different approaches. Hydrobiologia, 1999, 402, 291-307.

Wysocka-Diller J., Aisemberg G.O. \& Macagno E.R. A novel homeobox cluster expressed in repeated structures of the midgut. Dev. Biol., 1995, 171 (2), 439-447. 